QUAL CIDADANIA, QUAL DEMOCRACIA, QUAL EDUCAÇÃO?

WHICH CITIZENSHIP, WHICH DEMOCRACY, WHICH EDUCATION?

José Rodrigues 1

Resumo $\mathrm{O}$ texto tem o fito de dialogar criticamente com o texto Revisitando o conceito de cidadania: notas para uma educação politécnica, de Adriana Gleisler, que procura "recolocar a questão do significado da cidadania hoje", na perspectiva de "identificar a que conceito de cidadania a noção de politecnia se filia". Nesse sentido, o presente texto, organizado em três momentos, pretende oferecer uma visão alternativa àquela posta pela autora. Na seção, Qual cidadania, em qual democracia, discutimos sumariamente os conceitos de cidadania e democracia, articulando-os aos respectivos contextos da chamada redemocratização e do governo Lula. Procuramos, com isso, revelar a opção política das forças que trabalharam pela 'transição democrática', atualizadas - de certa forma - no atual governo. Em Qual educação politécnica, retomamos o conceito de educação politécnica e, a partir dele, tentamos mostrar como a opção política de cariz aliancista acabou por arrefecer o ímpeto socialista, desarmando o discurso educacional crítico de sua mais importante base: a luta pela superação da sociedade de classes. Finalmente, em As duas faces de uma miragem, procuramos (re)apresentar de forma sintética a relação de subordinação política tanto no aspecto mais geral, quanto no aspecto do debate educacional.

Palavras-chave educação politécnica; cidadania e educação; luta de classes e educação.
Abstract The text has the intent of dialoguing critically with the text Revising the concept of citizenship: notes for a polytechnic education, of Adriana Gleisler, which seeks to "putting forward again the question of the meaning of citizenship", in the perspective of "identifying to which concept of citizenship the notion of polytechnic is affiliated". In this sense, this text, organized in three moments, intends to offer an alternative view to the one posed by the author. In the section, Which citizenship, in which democracy, we briefly discuss the concepts of citizenship and democracy, articulating them to the respective contexts of the so-called redemocratization and the Lula government. We seek, with this, to reveal the political option of the forces that work for the 'democratic transition' updated - in a certain manner - in the current government. In Which polytechnic education, we retake the concept of polytechnic education and, from it, we try to show how the political option of the alliancist countenance ended up cooling the socialist impetus, disarming the critical educational speech of its most important base: the fight for the overcoming of the class society. Finally, in The two faces of a mirage, we seek to present (once again) in a synthetic manner, the relation of political subordination both in the more general aspect and in the educational debate aspect.

Key words polytechnic education; citizenship and education; class fight and education. 


\section{Considerações preliminares}

Na década de 1980, toda a cena política brasileira, inclusive os campos da saúde e da educação, passava por um processo catártico de repensar profundamente o seu passado recente e de instaurar, a partir daí, as novas bases para a reconstrução de uma cidadania usurpada, no contexto de uma democracia restringida por ocasião do golpe civil-militar perpetrado em 1964.

No campo educacional, o centro do debate dizia respeito à necessária reestruturação do 'sistema educacional' brasileiro erigido durante o regime autoritário, instaurado pelo golpe militar de 1964. Nesse contexto histórico, instigado por Dermeval Saviani, emerge com grande força o debate sobre a concepção de educação politécnica².

O texto Revisitando o conceito de cidadania: notas para uma educação politécnica, de Adriana Gleisler, como indicado pelo próprio título, inscreve-se na atualização do debate da politecnia, provavelmente proporcionado pelo debate em torno da 're-reforma' da educação profissional no governo Lula da Silva3 .

Dado que a concepção de politecnia inscreve-se na tradição socialista de combate às perspectivas burguesas de educação e que se faz necessário o debate, ainda insuficiente, sobre os rumos da sociedade brasileira sob um governo de um partido que se reivindica dos trabalhadores, julgamos perfeitamente oportuna a publicação do texto em questão. Portanto, é mister a discussão sobre os conceitos (e as práticas) fundamentais da sociedade, como cidadania e educação, democracia e socialismo. Dialogar, em vez de confrontar, com o texto de Geisler é o que pretendemos.

O texto de Adriana Geisler tem por objetivo "recolocar a questão do significado da cidadania hoje" na perspectiva de "identificar a que conceito de cidadania a noção de politecnia se filia" (p. 1). Nesse sentido, a autora revela, primeiramente, a relação entre educação e contexto político: “Indissociável da sociedade, a escola brasileira reproduz o processo histórico excludente que tem se caracterizado por uma democracia restrita e pelas estruturas de poder e de classe que foram se cristalizando no Brasil" (p. 23).

Em seguida, o texto procura conceituar melhor a "cidadania brasileira", que pode ser sintetizada da seguinte forma:

“Erguida sob um longo processo de colonização e mantida sob a égide de uma modernização conservadora que sobrevive às custas de uma democracia restrita e de períodos de transformismo, a sociedade brasileira, bem como sua estrutura educacional, evidencia evidenciam sua filiação à concepção liberal burguesa de cidadania" (p. 27). 
Por outro lado, para Geisler, apoiada em Saviani (2003), a concepção de educação politécnica se contrapõe à lógica do mercado e ao ideário pedagógico do capital. Mais adiante, a autora, apoiada em Ramos (2005), afirma:

“A profunda desigualdade social que se manifesta no desequilíbrio de forças entre capital e trabalho se decompõe (e se realimenta) da desigualdade educacional expressa, comumente, na dicotomia entre o ensino com vistas à 'competência' para trabalho produtivo e o que, dedicado ao trabalho intelectual, volta-se para a formação das elites dirigentes do país" (p. 23).

Finalmente, o texto conclui, articulando cidadania e educação politécnica:

"Ampliando o conceito de cidadania em uma perspectiva psicossocial, tendo como referência o fortalecimento dos movimentos sociais da década de 1980, nos foi possível reconhecer na concepção politécnica sua inscrição a um sentido coletivo e emancipatório de cidadania que denominamos de 'cidadania como pertencimento'" (p. 27).

Ora, precisamente nestes dois últimos excertos, ocultam-se pelo menos dois aspectos articulados, para os quais apresentaremos uma visão alternativa.

Primeiramente, é necessário ratificar que se, de um lado, o debate brasileiro sobre a educação politécnica não se articulou com a concepção liberal burguesa de cidadania, por outro lado, é possível identificar uma subordinação política (de ordem tática) do debate educacional, em geral, e de uma perspectiva da politecnia, em particular, aos limites da 'democracia formal liberal', na esperança de que esta se consubstanciaria em uma 'democracia substantiva de caráter social-democrata'. Nesse contexto, discurso e prática política revolucionários - originados na pulsão socialista - precisavam ser fortemente contidos para não ameaçar a frente (e a face) política (do discurso) 'progressista'.

Ou seja, a dimensão socialista da educação politécnica precisou ser mitigada de forma a não ameaçar a aliança do pensamento pedagógico 'progressista' com aquelas forças políticas burguesas, isto é, do capital, que também aspiravam reconstituir a democracia formal no Brasil e, de alguma forma, talvez diminuir "a profunda desigualdade social que se manifesta no desequilíbrio de forças entre capital e trabalho" e que "se decompõe (e se realimenta) da desigualdade educacional" (Geisler, p. 23).

Assim, se a subordinação política do discurso pedagógico progressista permaneceu oculta (ou recalcada) no período de implantação do neoliberalismo no Brasil, acabou por emergir (ou retornar) no contexto da re-reforma da educação profissional promovida pelo governo Lula da Silva. 
Para desenvolver um pouco mais esta visão alternativa, este ensaio desenvolve-se em três momentos, a saber: "Qual cidadania em qual democracia", "Qual educação politécnica", e "As duas faces de uma miragem".

Na primeira seção, discutiremos sumariamente os conceitos de cidadania e democracia, articulando-os aos respectivos contextos da chamada redemocratização do governo Lula da Silva. Procuraremos, com isso, revelar a opção política das forças que trabalharam pela 'transição democrática', atualizadas - de certa forma - no atual governo do Partido dos Trabalhadores.

Na segunda seção, retomaremos o conceito de educação politécnica e, a partir dele, tentaremos mostrar como a opção política de cariz aliancista acabou por arrefecer o ímpeto socialista, desarmando o discurso educacional crítico de sua mais importante base: a luta pela superação da sociedade de classes.

Finalmente, à guisa de considerações finais, na terceira seção procuraremos (re)apresentar de forma sintética a relação de subordinação política tanto no aspecto mais geral, quanto no aspecto do debate educacional

\section{Qual cidadania em qual democracia}

Como se sabe, a idéia de cidadania, referindo-se à qualidade daquele que pertence à 'cidade', isto é, de quem tem a permissão de participar da vida política, floresceu em diversos períodos da história - na Grécia e na Roma Antigas, nos burgos da Europa medieval, nas cidades renascentistas ${ }^{4}$.

Embora o conceito contemporâneo de cidadania possua características próprias, um aspecto precisa ser logo destacado e criticado: a origem e a permanência de seu caráter extremamente restrito e restritivo. Com efeito, na Grécia Antiga, a cidadania - isto é, a participação na polis - estava restrita a uma pequena parcela da população; excluídos dela estavam as mulheres e aqueles que trabalhavam, isto é, os escravos. Na virada do século XVII para o XVIII, John Locke contribui decisivamente para o conceito de cidadania (restrita) na nascente sociedade capitalista, ao considerar em sua definição a liberdade individual e o direito de propriedade privada, com o fito de assegurar à burguesia os direitos políticos que lhes eram negados pela nobreza, ainda a classe dominante.

Na época contemporânea, isto é, nas sociedades capitalistas, notadamente no século XX, são admitidos com certa naturalidade os conceitos de 'cidadania formal' e de 'cidadania substantiva'.

Cidadania formal pode ser definida como a condição de membro de um Estado-nação democrático, em função disso, portador de direitos políticos. Na 
tradição liberal, segundo Bobbio (2004, p. 326-327), “as definições de democracia tendem a resolver-se e a esgotar-se num elenco mais ou menos amplo (...) de regras de jogo, ou, como também se diz, de "procedimentos universais"'. Ora, o que se entende hoje por cidadania formal é precisamente a pertença individual (e, de certa forma, também coletiva) às regras do jogo ${ }^{5}$.

A partir da Segunda Guerra mundial, contudo, emerge o conceito de cidadania substantiva, que passa a englobar um leque relativamente amplo de direitos - civis (fundados na idéia de liberdade individual, originada no século XVIII), políticos (isto é, o direito de participação dos indivíduos no governo, a partir da constituição de partidos políticos, do Poder Legislativo etc., originados no século XIX) e sociais (relativos ao direito de acesso a serviços públicos universais, notadamente educação, saúde, que, em tese, garantiriam condições mínimas de vida, isto é, de trabalho).

É óbvia a relação do conceito de cidadania substantiva com a constituição, na Europa Ocidental, do chamado Estado de bem-estar social e, nesse sentido, poderíamos denominar este tipo de pertença a um Estado-nação caracterizado como estado de bem-estar social como 'cidadania substantiva social-democrata'6.

No Brasil, em fins da década de 1970, quando o dito 'milagre econômico' da ditadura civil-militar mostra-se um rotundo fracasso, sem falar na óbvia negação das 'regras do jogo' democrático, inicia-se um lento e gradual processo de 'distensão' e 'transição democrática'.

A adesão, mais ou menos crítica, de grupos políticos e sociais ligados à classe trabalhadora a esse processo, que acabou por conduzir José Sarney, quadro oriundo das hostes ditatoriais, à presidência da República, revelouse o primeiro aspecto de uma miragem. Nas palavras de Roberto Leher:

“O terreno político foi redesenhado: o pomo da discórdia não estaria mais centrado no modelo econômico do governo militar, mas no 'autoritarismo'. Com isso, o campo de conciliação foi redefinido. Mesmo aqueles que sustentaram o modelo econômico dependente e concentrador poderiam se credenciar como interlocutores da 'transição', desde que manifestassem apoio à redemocratização, uma conversão fácil, posto o esgotamento político-econômico dos governos militares" (Leher, 2001, p. 159-160).

Em poucas palavras, setores da classe trabalhadora submeteram-se à direção política da burguesia dissolvendo-se politicamente em uma frente ampla de caráter anti-ditatorial. Uma frente que preconizava, tão-somente, o retorno à democracia formal. Setores sociais 'progressistas' - em grande parte integrados por frações da classe trabalhadora e de segmentos médios intelectualizados - miravam a idéia, isto é, portavam a crença de que o retorno à democracia formal, ou seja, a reconstituição da cidadania formal 
liberal, conduziria necessariamente à construção de uma democracia substantiva social-democrata. Afastada pela aliança de classes, a identidade de classe trabalhadora e a luta pelo socialismo eram relegadas a um futuro longínquo. Esta perspectiva 'progressista' lembra as críticas elaboradas por Marx e Engels, no Manifesto comunista, ao socialismo e ao comunismo crítico-utópicos:

\footnotetext{
“Os inventores destes sistemas vêem, na verdade, o antagonismo das classes, bem como a ação dos elementos de dissolução a própria sociedade existente. Mas não vislumbram, no proletariado, nenhuma atividade histórica, nenhum movimento próprio" (Marx e Engels, 1998, p. 42).
}

Eis o primeiro aspecto da miragem: a negação à autonomia política da classe trabalhadora na necessária luta contra a ditadura civil-militar do capital, principalmente a partir de fins da década de 1970. Uma luta que, ao fim e ao cabo, pretendia apenas restituir a democracia formal liberal e a sua cidadania civil e política ${ }^{7}$.

Nesse sentido, a idéia de cidadania acaba por cumprir uma função ideológica, pois oculta o monopólio, a ditadura, que se dá a partir e através da propriedade privada dos meios de produção, isto é, do poder econômico (Welmovicki, 2001).

\section{Qual educação politécnica}

Como já foi apontado, na década de 1980, o cenário educacional brasileiro foi palco de um forte debate, em cujo centro encontrava-se em disputa a reestruturação do 'sistema educacional brasileiro' 8 . Foi nesse contexto histórico que (re)nasceu no cenário educacional brasileiro o debate sobre a concepção de educação politécnica, trazido por Dermeval Saviani. Com esse movimento, preparavam-se os educadores para produzir uma nova estrutura para o ensino no país, a ser discutida durante os debates da Assembléia Nacional Constituinte, que selaria o fim da ordem estabelecida em 19649, retornando-se à democracia formal.

A partir da atuação de Saviani ${ }^{10}$, no início da década de 1980, as concepções pedagógicas de Marx e Gramsci11 - elaboradores originais da proposta de educação politécnica - são amplamente divulgadas ${ }^{12}$.

Portanto, pode-se afirmar que o debate sobre a politecnia tomou vulto no Brasil, dentro do contexto da chamada redemocratização política, na busca de reestruturação da educação nacional, atingindo seu ápice no final 
dos anos 80 e início dos 90. Uma vez instituída a nova carta constitucional, os educadores passaram a envidar esforços na elaboração de uma nova LDB, só promulgada em dezembro de $1996{ }^{13}$.

Em que pesem as diferentes propostas, a concepção de politecnia pode ser sintetizada em três eixos fundamentais: dimensão infra-estrutural, dimensão socialista e dimensão pedagógica ${ }^{14}$.

A dimensão infra-estrutural da concepção politécnica de educação agrega os aspectos relacionados ao mundo do trabalho, especificamente os processos de trabalho sob a organização capitalista de produção, e, conseqüentemente, a questão da qualificação profissional. Pode-se afirmar, grosso modo, que a discussão sobre a qualificação profissional, com base nas novas formas de organização do processo de trabalho, era o foco da discussão da educação politécnica. Nesse sentido, a dimensão infraestrutural da concepção politécnica de educação se relaciona intimamente com as mudanças na produção e com suas correlatas alterações científicas e, principalmente, tecnológicas. A questão nodal era, então, procurar esclarecer como as inovações tecnológicas 'implicariam' a politecnia, ou seja, em que medida as mudanças nos processos de trabalho estariam contribuindo para a efetivação de uma formação politécnica. Enfim, a concepção politécnica de educação propõe, através de sua dimensão infra-estrutural, a identificação de estratégias de formação humana, com base nos modernos processos de trabalho, que apontem para uma reapropriação do domínio do trabalho, somente possível a partir das transformações tecnológicas.

O segundo vetor do debate brasileiro sobre a educação politécnica dimensão socialista - busca expor a profunda relação entre essa concepção de formação humana e um projeto de construção de uma sociedade sem classes. A denominação dimensão 'utópica' foi cunhada, em 1993, por ocasião do estudo que pretendia apreender as continuidades e também as descontinuidades do debate sobre a politecnia no Brasil (Rodrigues, 1998). Em 2005, no debate sobre a 're-reforma' da educação profissional cometida pelo governo Lula da Silva, mantivemos a mesma designação. No estudo inicial, o adjetivo não tinha como objetivo indicar que a politecnia seria um ideal irrealizável, uma proposta historicamente desenraizada. Ao contrário, a palavra foi escolhida em reconhecimento da importância das propostas educacionais inicialmente postas por Robert Owen, continuadas e ampliadas por Marx (ver, em particular, Marx, 1994) e também por Gramsci, e, fundamentalmente, pelo intenso desejo, expresso pelos socialistas utópicos, de contribuir para que a humanidade alcançasse uma sociedade sem classes (mesmo que politicamente eles incorressem nos erros apontados por Marx, que apresentamos anteriormente). 
Contudo, diante do discurso redivivo de que a história 'chegou a fim', ou de que a democracia é um 'valor universal', optamos agora por denominar essa dimensão de 'socialista'. Para autores brasileiros, no auge do debate da politecnia, seria o projeto socialista-revolucionário de uma nova sociedade que possibilitaria, por um lado, proporcionar unidade teórico-política à concepção politécnica de educação e, por outro, impedir a sua 'naturalização', isto é, impedir o equívoco de se entender que a formação politécnica é o caminho 'natural' demandado pelo modo de produção capitalista. Em outras palavras, a politecnia - apoiada em sua dimensão socialista - representaria uma profunda ruptura com o projeto de educação profissional e, fundamentalmente, com o projeto de formação humana postos pela sociedade burguesa: “a concepção de ensino e formação politécnica é, antes de tudo, uma crítica radical ao projeto excludente, elitista e diferenciador do ensino e da formação, desenvolvido na sociedade capitalista" (Frigotto, 1991, p. 270).

Ora, como caminhar para uma progressiva explicitação do modus operandi de uma escola que se paute numa orientação politécnica, sem recair em proposições abstratas, isto é, historicamente desenraizadas? ${ }^{15} \mathrm{Na}$ opinião dos autores em tela, além do permanente estudo da dimensão infraestrutural, além da consciência de que nenhum estudo ou pesquisa poderá substituir a práxis educativa desenvolvida a partir do horizonte da politecnia, a construção da concepção de educação politécnica precisaria, necessariamente, estar embasada em práticas pedagógicas concretas que, por sua vez, deveriam apoiar-se em profundas reflexões teóricas sobre o papel e a natureza da educação na sociedade capitalista. Posto isso, era consenso que a formação politécnica deveria buscar romper com a profissionalização estreita e também com a educação geral e propedêutica, livresca e descolada do mundo do trabalho't6.

Enfim, embora os autores não identificassem polivalência com politecnia, posto que a polivalência representaria apenas um momento necessário à politecnia17, ficava mais ou menos implícito que haveria margem para um acordo supraclassista em torno do caráter 'progressista' da reestruturação produtiva ${ }^{18}$, obviamente, desde que reprimida a dimensão socialista. Em poucas palavras, a superação do padrão taylorista-fordista de organização do trabalho e de formação profissional interessaria tanto à burguesia (dita nacional) quanto à classe trabalhadora. Enfim, acenada pelos 'apologetas' da especialização flexível, a virtuosidade do desenvolvimento das forças produtivas foi abraçada como interesse supraclassista. Eis a segunda face de uma miragem. 


\section{As duas faces de uma miragem}

Desde 1989, o Brasil mergulhou numa conjuntura política bastante adversa ao debate e à defesa da educação politécnica. Com efeito, as eleições de Fernando Collor e, em seguida, Fernando Henrique Cardoso para a presidência marcaram o ingresso das políticas neoliberais ${ }^{19} \mathrm{e}$, conseqüentemente, deram início rapidamente a um período de constrição dos direitos sociais, tão logo esses tinham sido inscritos na Constituição de 1988.

Tais políticas vêm, de um lado, no rastro da crise do padrão de acumulação fordista, iniciada em fins da década de 1970, e na conseqüente estruturação do novo padrão de acumulação flexível; de outro, no esteio da crise do pensamento anticapitalista, diante da derrocada da União Soviética e do restabelecimento da economia capitalista em todo o Leste Europeu.

Aliás, o atual governo do Partido dos Trabalhadores significa um novo desafio aos socialistas, pois, além de promover a continuidade (e, em certos casos, o aprofundamento) das políticas macroeconômicas, sociais e educacionais dos governos neoliberais anteriores, a presidência de Lula da Silva vem contribuindo ainda mais para o fortalecimento da prática política aliancista, na medida em que conseguiu, de fato, subordinar os interesses históricos da classe trabalhadora à lógica do capital financeiro e das demandas (restringidas) de determinado capital industrial (exportador de mercadorias de baixo valor e tecnologia agregados $)^{20}$.

A sociedade contemporânea encontra-se diante do seguinte e crescente dilema: por um lado, crescem as possibilidades materiais e tecnológicas para a dilatação do reino da liberdade; por outro, diminuem os direitos sociais, ampliando o reino da necessidade. Ou seja, o avanço incomensurável do desenvolvimento das forças produtivas, que poderiam servir de base à educação politécnica, acaba por esbarrar nos limites da organização da vida social.

Além disso, e de forma mais específica, dois aspectos se somam, desarmando o discurso educacional crítico de sua mais importante base. Em primeiro lugar, conforme discutimos na primeira seção deste ensaio, a tática de frente anti-ditadura militar, em prol de uma 'transição democrática', portanto passando ao largo de uma política de independência de classe, acabou por subordinar a luta pelo socialismo à visão etapista, de caráter reformista, que pretendia, primeiramente, a restauração de uma democracia formal, para, em seguida, lutar por uma constituição que assegurasse uma democracia substantiva, nos marcos de um Estado de bem-estar social. Ou seja, a tática da frente anti-ditadura militar articulou-se à estratégia reformista, típica da tradição do Partido Comunista Brasileiro (leia-se, stalinista), de aliança de classes. 
As disputas em torno do capítulo de educação, durante os trabalhos do Congresso Constituinte, e, em seguida, na elaboração da LDB, seguiram, de forma análoga, a mesma estratégia. O debate brasileiro da politecnia, de fato, ancorou-se (ilusória ou astutamente) no discurso apologético da especialização flexível, aliado à esperança de que a 'democracia formal' nos traria 'democracia substantiva', e no bojo dessa, um sistema educacional público, com um ensino médio universal, público, gratuito e obrigatório, suposta base jurídica e material para a construção da escola politécnica.

Em suma, a miragem da aliança de classes foi perseguida por dois caminhos: pela prática política, de caráter mais geral, e pelo discurso educacional, em particular. A educação "pública-gratuita-universal-e-democrática" seria caudatária da democracia formal reconstituída. Portanto, a concepção de educação (politécnica) precisaria ser castrada de seu ímpeto rebelde socialista para não afastar os supostos aliados da classe trabalhadora - a burguesia industrial interna interessada em democracia formal e em reestruturação produtiva com redução dos direitos sociais, isto é, constrição da cidadania substantiva.

Parafraseando um grande pensador21, precisamos afirmar que nossa proposta de ação política baseada na independência de classe, anti-aliancista, não é uma ilusão; que nossa proposta de educação (politécnica), marcada indelevelmente pela dimensão socialista, não é uma ilusão. Uma miragem seria acreditar que aquilo que a classe trabalhadora não lograr por si mesma, conseguirá como dádiva de seus exploradores.

\section{Notas}

1 Professor da Faculdade de Educação da Universidade Federal Fluminense e membro do Núcleo de Estudos, Documentação e Dados sobre Trabalho e Educação (Neddate-UFF). Doutor em Filosofia e História da Educação pela Unicamp e pesquisador do CNPq, em estágio de pós-doutoramento no Departamento de Ciência Política da Unicamp. <jrodrig@vm.uff.br>

2 Cabe assinalar que a Escola Politécnica de Saúde Joaquim Venâncio (EPSJV) tem lugar de destaque no debate. Aliás, precisamente em dezembro de 1987, durante o Seminário Choque Teórico, promovido pelo então Politécnico da Saúde Joaquim Venâncio, Saviani apresentou o texto Sobre a concepção de politecnia (Saviani, 1989), tornando-se um marco no debate brasileiro da área trabalho e educação.

3 Sobre a 're-reforma' da educação profissional e a correlata alteração da relação ensino médio/educação profissional, ver Rodrigues (2005a) e Frigotto, Ciavatta e Ramos (2005).

4 Sobre os conceitos de cidadania e democracia, ver Bottomore (1996), Bobbio (2004) e Lukes (1988). Ver também França (2005). 
5 Contudo, como o próprio Bobbio (2004, p. 327, grifo nosso) admite mais adiante, "todas as regras estabelecem como se deve chegar à decisão política e não o que decidir", ou melhor, em prol de quem se decide.

6 Ora, talvez precise ser destacado que as políticas sociais representam medidas contra-tendenciais à ampliação das desigualdades econômica, social e (por que não?) política produzidas 'normalmente' pela acumulação de riquezas oriunda da exploração capitalista sobre os trabalhadores.

7 Para França (2005, p. 124), o 'novo' sindicalismo, em suas greves de 1978, estava submetido à esta lógica. Luiz Marinho, então presidente do Sindicato dos Metalúrgicos do ABC, atual ministro do Trabalho de Lula da Silva, afirmou, em 1998: "as greves de 1978 eram realizadas para abrir espaços para a negociação. A ditadura impedia essa negociação. Toda a nossa briga em 1978 era pela negociação". Vale também apreender a noção de nova cidadania trabalhada por França, que por falta de espaço não abordaremos aqui.

${ }^{8}$ Mesmo concordando com Saviani (1996 e 1997), em suas análises que indicam a inexistência de um sistema educacional no Brasil, utilizamos neste texto a expressão 'sistema educacional' no sentido do senso comum, corrente, isto é, uma designação impressionista que abarca o conjunto das instituições escolares, consideradas indistintamente de sua dependência administrativa (pública ou privada, federal, estadual ou municipal) ou seus níveis e modalidades de atuação. Contudo, de uma maneira mais específica, temos em mente, ao utilizar a expressão sistema educacional, o conjunto das instituições públicas de ensino.

${ }^{9}$ Cabe destacar que, de fato, não ocorreu no país uma assembléia constituinte, posto que o Congresso Nacional eleito (inclusive tendo ainda entre seus membros senadores indicados pelo regime militar, os chamados senadores 'biônicos') acumulou as tarefas legislativas ordinárias à elaboração da nova carta constitucional, com todas as conseqüências advindas desse acúmulo de poder.

10 São relevantes as conseqüências da atuação de Saviani no Programa de Pós-Graduação em Educação da PUC-SP. Sobre a experiência, ver Saviani (2002).

11 É bastante relevante a leitura do educador italiano Mario Manacorda (1990 e 1991) sobre as obras de Marx e Gramsci para o debate sobre a educação politécnica no Brasil.

12 Nesse contexto, em 1984, coube a Gaudêncio Frigotto (1989), então orientando de Saviani naquela instituição, produzir o primeiro texto, A produtividade da escola improdutiva, no qual é abordada explicitamente a concepção de formação politécnica. A partir deste trabalho, diversos outros se seguiram, tais como os de Lucília Machado (1989) e Acácia Kuenzer (1988 e 1991), além de outros de autoria do próprio Frigotto (1991) e de Saviani (1989 e 2003). Nossa própria contribuição ao debate encontra-se em Rodrigues (1998 e 2005a).

13 Sobre o longo e complicado processo de elaboração da nova LDB (lei n 9.394), ver Saviani (1997).

14 Dado o foco do presente ensaio, daremos menor destaque precisamente à última das dimensões. Para uma análise mais completa, ver Rodrigues (1998).

15 Para uma crítica contundente ao escolacentrismo e à perspectiva do 'dever ser', ver Arroyo (1991). 
16 Para uma análise mais completa, ver Rodrigues (1998 e 2005a).

17 Sobre a relação polivalência e politecnia, ver Marx (1994), particularmente o capítulo XIII, em especial a nota 308 à p. 558).

18 Para uma visão crítica da reestruturação produtiva contemporânea, ver Harvey (1992).

19 Sobre o neoliberalismo, ver Boito Jr. (1999).

20 Para uma análise do governo Lula, ver Oliveira (2003), particularmente o ensaio O ornitorrinco, Petras (2005) e Boito Jr. (2005), particularmente os capítulos “Hegemonia neoliberal e sindicalismo no Brasil" e "A hegemonia neoliberal no governo Lula". Sobre a reforma da educação superior do atual governo, ver Rodrigues (2005b e 2006).

${ }^{21}$ Referimo-nos a Sigmund Freud (1997).

\section{Referências}

ARROYO, Miguel. 1991. Revendo os vínculos entre trabalho e educação: elementos materiais da formação humana. In: SILVA, Tomaz Tadeu (org.). Trabalho, educação e prática social: por uma teoria da formação humana. Porto Alegre: Artes Médicas, p. 163-216.

BOBBIO, Norberto. 2004. Democracia. In: BOBBIO, Norberto; MATTEUCCI, Nicola; PASQUINO, Gianfranco (orgs.). Dicionário de política. $5^{\mathrm{a}}$ ed. Brasília: EdUnB; São Paulo: Imprensa Oficial, v. 1, p. 319-329.

BOITO JR, Armando. 1999. Politica neoliberal e sindicalismo no Brasil. São Paulo: Xamã. 2005. O sindicalismo na politica brasileira. Campinas: Instituto de Filosofia e Ciências Humanas, Universidade Estadual de Campinas. (Trajetórias, n. 8).

BOTTOMORE, Tom. 1996. Cidadania. In: OUTHWAITE, William; BOTTOMORE, Tom (orgs.). Dicionário do pensamento social do século $X X$. Rio de Janeiro: Zahar, p. 73-74.

FRANÇA, Teones P. 2005. Mundo do trabalho e sindicalismo no Brasil (1988-2000): uma análise sobre as principais causas da crise sindical. Tese de Doutorado, Niterói: Instituto de Ciências Humanas e Filosofia, Universidade Federal Fluminense.
FREUD, Sigmund. 1997. O futuro de uma ilusão. Rio de Janeiro: Imago.

FRIGOTTO, Gaudêncio. 1989. A produtividade da escola improdutiva: um (re)exame das relações entre educação e estrutura econômico-social capitalista. $3^{a}$ ed. São Paulo: Cortez/Autores Associados.

1991. Trabalho-educação e tecnologia: treinamento polivalente ou formação politécnica? In: SILVA, Tomaz Tadeu (org.). Trabalho, educação e prática social: por uma teoria da formação humana. Porto Alegre: Artes Médicas, p. 254-274.

FRIGOTTO, Gaudêncio; CIAVATTA, Maria; RAMOS, Marise (orgs.). 2005. Ensino médio integrado: concepções e contradições. São Paulo: Cortez; Rio de Janeiro: Escola Politécnica de Saúde Joaquim Venâncio, Fundação Oswaldo Cruz.

HARVEY, David. 1992. Condição pós-moderna: uma pesquisa sobre as origens da mudança cultural. $5^{\text {a }}$ ed. São Paulo: Loyola.

KUENZER, Acácia. 1988. Ensino de $2^{\circ}$ grau: o trabalho como princípio educativo. São Paulo: Cortez.

1991. Ensino médio: uma nova concepção unificadora de ciência, técnica e ensino. In: GARCIA, Walter e CUNHA, 
Célio (coords.). Politecnia no ensino médio. São Paulo: Cortez; Brasília: SENEB, p. 113-123.

LEHER, Roberto. 2001. Tempo, autonomia, sociedade civil e esfera pública: uma introdução ao debate a propósito dos 'novos' movimentos sociais na educação. In: GENTILI, Pablo; FRIGOTTO, Gaudêncio (orgs.). A cidadania negada: políticas de exclusão na educação e no trabalho. $2^{\text {a }}$ ed. São Paulo: Cortez; Buenos Aires: Clacso, p. 145-176

LUKES, Steven. 1988. Democracia. In: BOTTOMORE, Tom (org.). Dicionário do pensamento marxista. Rio de Janeiro: Zahar, p. 97-98.

MACHADO, Lucília. 1989. Politecnia, escola unitária e trabalho. São Paulo: Cortez/ Autores Associados.

1991. A politecnia nos debates pedagógicos soviéticos das décadas de 20 e 30. Teoria \& Educação, n. 3, p.151-174.

MANACORDA, Mario A. 1990. O princípio educativo em Gramsci. Porto Alegre: Artes Médicas.

1991. Marx e a pedagogia moderna. São Paulo: Cortez/ Autores Associados.

OLIVEIRA, Francisco de. 2003. Crítica à razão dualista: o ornitorrinco. São Paulo: Boitempo.

MARX, Karl. 1994. O capital: crítica da economia política. $14^{\mathrm{a}}$ ed. Rio de Janeiro: Bertrand Brasil, t. 1, v. 1.

MARX, Karl; ENGELS, Friedrich. 1998. Manifesto do Partido Comunista. São Paulo: Cortez.

PETRAS, James. 2005. Brasil e Lula: ano zero. Blumenau: Edifurb.

RODRIGUES, José. 1998. A educação politécnica no Brasil. Niterói: EdUFF. 2005a. Ainda a educação politécnica: o novo decreto da educação profissional e a permanência da dualidade estrutural. Trabalho, Educação e Saúde, v. 3, n. 2, p. 259-282.

2005b. A nova educação superior brasileira no padrão de acumulação flexível. In: QUARTIERO, Elisa Maria; BIANCHETTI, Lucídio (orgs.). Educação corporativa, mundo do trabalho e do conhecimento: aproximações. Santa Cruz do Sul: Edunisc; São Paulo: Cortez, p. 246-273.

2006. Frações burguesas e a educação superior no governo Lula. In: $3^{\circ}$ Congresso Latino-Americano de Ciência Política, Campinas. Democracia e desigualdades. Campinas: Unicamp/Associação Latino-Americana de Ciência Política, v. 1, p. 1-27. CD-ROM.

SAVIANI, Dermeval. 1989. Sobre a concepção de politecnia. 1987, Rio de Janeiro. Rio de Janeiro: Politécnico da Saúde Joaquim Venâncio.

1996. Educação brasileira: estrutura e sistema. $7^{\text {a }}$ ed. Campinas: Autores Associados.

1997. A nova lei da educação: LDB - trajetória, limites e perspectivas. Campinas: Autores Associados.

2002. Doutoramento em educação: a experiência da PUC-SP. Educação: do senso comum à consciência filosófica. $14^{\mathrm{a}}$ ed. rev. Campinas: Autores Associados, p. 101-105.

2003. O choque teórico da politecnia. Trabalho, Educação e Saúde, v. 1, n. 1, p. 131-152.

WELMOVICKI, José. 2001. Fórum Social Mundial: morte ao capitalismo ou capitalismo cidadão? Marxismo Vivo, n. 3. 
